\title{
The Alienated Narration of Mahler's Music
}

\author{
Ning $\mathrm{Wu}$ \\ School of Arts \\ Southeast University \\ Nanjing, China 210018 \\ School of Music \\ Qufu Normal University \\ Rizhao, China 276826
}

\begin{abstract}
Mahler was the first composer in Western music history to convert music into a tool of social criticism. He used irony to reveal the value of life, social exclusion and dangerous environment. The Fin-de-Siècle decadent sentiment in Mahler's music, the profound dilemma of grief and joy, and the politicized representation of sound all reflect profoundly the alienation of society at that time and highlight its artistic charm with an alienation narrative of subverting the tradition.
\end{abstract}

Keywords-Mahler; alienation; narrative; decadence; irony; subversion

\section{INTRODUCTION}

Mahler was the first composer in Western music history to convert music into a tool of social criticism. He used irony to reveal the value of life, social exclusion and dangerous environment. The Fin-de-Siècle decadent sentiment in Mahler's music, the profound dilemma of grief and joy, and the politicized representation of sound all reflect profoundly the alienation of society at that time and highlight its artistic charm with a unique alienation narrative.

\section{CONCEPT OF ALIENATION}

The concepts of alienation belong to the category of philosophy and sociology, and it means estrangement, transfer and separation in foreign language. Scholars in different historical periods have different interpretations of the nature that alienation reflects.

Alienation theory sprouted in medieval literature and gradually came into being in modern western philosophy since the renaissance. Social contract theory holds that alienation is a negative activity that damages individual rights, that is, the waiver or transfer of rights. Rousseau once pointed out in Emile that "civilization corrupts people; Deviating from nature leads to depravity; Man becomes a slave to his own creation", which reveals the fact that people's social activities and their products are alienated, thus deepening the connotation of the concept of alienation on the double relations between people and society and between people and nature. Alienation is mentioned in German classical philosophy as the height of philosophy, and Hegel's alienation thought is manifested in his criticism of "positivity" of Christianity, which he believes becomes a rigid alien force that oppresses people in turn. Finally, Marx criticized the previous alienation theory of non-scientific forms and revealed the essence of alienation. Before Marx, all kinds of alienation revealed by people basically remained in the external phenomenon. Marx revealed the essence of alienation that determines the external phenomenon of alienation and that is alienated labor or labor alienation.

Alienation is seen as a kind of living condition of human beings in Marx's theoretical system, in which labor becomes the opposite of slavery and suppression of human beings as an alien existence. It is an alien transcendental force that not only permeates people and their own labor, but also manifests itself in some social factors, traditional institutional culture and other aspects. Alienation is a social phenomenon, in which people and society, others and id become lonely and antagonistic to each other with the selfloss and variation of human spirit.

Alienation has spread from economic and political fields to moral, psychological, pathological science, technology, literature and art and so on among western scholars in 1980s since Marx proposed the alienated labor system.

\section{ALIENATION VIEW OF THEODOR W. ADORNO}

Theodor W. Adorno (1903-1969) is one of the most important representatives of western Marxism whose research field involves psychology, philosophy and music sociology. And he is the most qualified philosopher and sociologist to comment on music in the 20th century, as well as the expert to study Mahler in the west.

"The bourgeois enlightenment movement was aimed at liberating man's rationality from ignorance and myth by conquering nature, but enlightenment itself has turned to its own negative side with the control of human beings over nature." Adorno once wrote in dialectics of enlightenment. Alienation has taken place in human society. Human society which was originally controlled by human beings has become a kind of extraordinary power to control human beings. Human beings are powerless in front of it and can only be subject to it.

Adorno believes that the essence of music is embodied in the specific relationship between music and society which is the source of music art from a sociological point of view. Music works are inextricably linked with the society in 
which they are located no matter in which era. If Beethoven's music showed "bourgeois heroic ideal", then Mahler's music pointed to the decadent social situation at that time. Adorno thinks that the more profound music expresses society, the more it will not shy away from social orientation, and the conflict in music is just some manifestation of social conflict. Art is not a simple imitation, reproduction and reflection of society, but is something different from social reality through a way of alienation.

As a result of the alienation of human society at the end of the 19th century, the relationship between human beings and the alien power that controls them, namely the alienated society, will become increasingly alienated and hostile. Therefore, music in this period was increasingly alienating from society and becoming the existence of social alienation. Its essence is the negation of society and the established reality, which is the "protest" and "rebellion" of the alienated society.

\section{Social CAUSES OF MAHLER Music}

Mahler lived in the late stage of European worldliness in the late 19th century and the early 20th century, when the decadent thoughts of "Fin-de-Siècle" and lost value spread everywhere. The culture in this period was complicated and the society is unstable, Mahler who came from a humble origin, had a rough life and knowing the sufferings of human beings, deeply sympathizes with people who were struggling in the abyss of misery. He often quoted Russian writer Dostoevsky to express his mood: "how can I feel happy when there are other creatures on the earth who are suffering ?" Mahler's own Jewish identity made him unable to integrate into the wonderful society which he yearned for. He was confronted with all kinds of difficulties of antiSemitism, and was exiled and politically alienated in life.

Therefore, compared with Beethoven who eulogized "freedom, equality and fraternity" in the rising period of the capitalist class, Mahler, who was in the era of imperialism when the bourgeoisie completely declined and decayed, didn't put a fantastic coat on the times in which he lived. Mahler unceremoniously revealed the sufferings of people and conflicts among different classes in society at that time, which bound to be full of doubt, confusion and despair, even satire and ridicule. Cruel and alienated social reality has created the unimaginable characterization of alienation narrative in Mahler's works.

\section{CHARACTERIZATION OF MAHLER'S ALIENATION NARRATIVE IN MUSIC}

\section{A. Decadence}

The word decadence comes from the Latin declineia, which has existed in the mythological traditions of ancient India, Greece and Rome as early as, and it expresses a kind of fear of time passing and declining fate. Although the modern concept of decadence includes the sense of crisis about time, the uneasiness and fear before the world goes to disaster, Mahler's music was added a layer of active resistance spirit, which is consistent with Nietzsche's view.
Negative emotions occupy the dominant position in the sense of decadence, which contain some positive resistance emotions at the same time. The decadent individuals are not totally addicted to depression, but brave to resist. Therefore, rebellion becomes a potential passion in decadence.

Mahler's musical thoughts were largely influenced by the great philosophers who lived at the same time with Mahler in history, and they were Nietzsche, Schopenhauer, and the psychologist Freud.

Nietzsche and Schopenhauer's philosophy are fundamentally pessimistic, but they were different. Schopenhauer believed that all life was painful in essence and that people should consciously deny the will of life and enter the realm of liberation similar to Buddhism "nirvana". And this kind of pure negative will of life created Mahler's religious plot of being born from the death. Nietzsche who relies on Dionysian spirit and strong will advocated overcoming the tragedy of life with passionate emotional appeal and truly laughing at all tragedies. It is a kind of positive creative power, which was reflected in Mahler's struggle and resistance against cruel reality.

Similarly, as a representative figure in the late romantic period, Mahler's music inevitably has a kind of mood at the Fin-de-Siècle in which the tone enveloped is sad and hopeless, but sometimes generate rebelled stubbornly and unyielding. His music became a refuge for many sensitive souls after experiencing hardships and turmoil. Mahler's symphony is a mixture of despair and longing, mixture of firmness and perplexity, coexistence of fierce and quiet, profound and naive; tangle and open-mindedness, imagination and the surge of sadness and happiness of reality. It's true that it consists one hundred tastes in life, and comprising everything in life experience.

Therefore, the decadent image in Mahler's music is not purely negative, but with some positive aspects. Decadence also means Unwilling to endure loss and gone. We always hear the final generous singing and triumphant cheering after sad sorrow in Mahler's symphony.

\section{B. Irony}

Secondly, the dissimilation in Mahler's music has sharp irony and bitter mockery. According to Samuel Johnson's definition, it refers to saying one thing, but it means another thing. It means looking at some positive things with different eyes, or recognizing that there are negative shadows in positive things. The deliberate satire of "irony" is not without precedent in the music history, but Mahler's deep, sharp and extensive penetration is unprecedented. Mahler's sarcastic attitude is very ambiguous, which hides deep anxiety in a protective irony level. It is a highly complex attitude towards life, which is not a high-altitude and condescending taunt but a satirical object that includes itself. Mahler's irony is often the distortion and treatment of the previous music elements and popular music materials at that time. It has a deep connection with tradition, and can be said that it uses its own music to comment on its previous music. It used traditional materials, but made its own unique treatment 
There suddenly came the laughing of woodwind in a seemingly sad funeral March, followed by a coarse and cheerful country band in the third movement of Symphony No.1. This seemingly "nonsense" music arrangement revealed how much absurdity and perversity of life. March for victory and triumph became a depressing alienation signal (artistic songs "the bed number", "the little drummer") or simply become ferocious and vicious (symphony No.6) in Mahler's hand. Healthy country glee or graceful waltz seems to have ominous omen due to the addition of strange discordant sound or the addition of stimulating grotesque timbre. The third movement of symphony No.2 is also full of classic irony and distortion, which comes from Mahler's own artistic song "saint Anthony's sermon to fish". The priest saint Anthony found the church empty during his sermon, so he went to the river bank to preach to the fish school. All kinds of fish listened with relish, but they were still palpable, and nothing changed after listening to the sermon. The whole story is absurd of course, and it is full of irony and mockery of religious sermons.

Playful exaggeration, mocking distortion and uncanny grotesque shadows in Mahler's music have directly influenced expressionism in later music. Schoenberg, a descendant of the last generation, who was fond of Mahler's teachings and got encouragement and support, eventually pushed music to the road of modernism. And the trace of Mahler music can be traced in the writings of some famous modern composers such as Berg, Britton and Shostakovich. Shostakovich regarded Mahler as his favorite composer and even said that the source of the special bitter irony in his music was Mahler.

\section{Subversion of the Traditional Structure}

Bach, Mozart and Beethoven spread to Brahms the orthodox idea of artistic music that is unity, conciseness, logic and coherence. Mahler's music creation obviously abandons that and goes to the opposite side which is mixing, twisting, scattering and breaking.

1) Emergent music presentation: According to Adorno, Mahler's symphony has the characteristics of fiction, and fresh factors can appear at any time as novel. It is different from the drama in which the wholeness is always above the section and not bound by the foretelling of the drama. Mahler's symphony is full of surprising and unpredicted factor, and new materials are constantly introduced into it, which is absolutely absent in Beethoven's symphonies whose structure attracts much attention.

Wu Weixi once commented Mahler's symphony No.6 in this way: "Compared with the German symphony based on dramatic logic in the classical-romantic period, this work is just like a novel with many roles and exquisite descriptions. Several groups of symbolic leading motives and their deformation are just like the main characters in the story running through the whole song."

Indeed, Mahler's symphony is obviously narrative, and the audience can really feel the montage scenes switching, the rapid progress of the plot and the successive appearances of different characters in the plot.
It can be said that the music conception of Mahler symphony is significantly different from that of classical symphony. The overall conception precedes the theme conception in classical music works in classical music works. Music as a whole can produce themes, and has a dialectical relationship with the theme to some extent. On the contrary, Mahler focuses on each distinctive and separate part (just like the characters or events in the novel), rather than the overall structure. Therefore, Mahler's works are a kind of " bottom - up" (that is, the first part is followed by the whole) structural way, and this creative way is incredible for classical musicians who take " top - down" (that is, the first part is followed by the whole) structural way as the fundamental principle.

2) Characteristic artistic treatment - breakthrough, suspension and completion: "Breakthrough" is the fragment of the structural wall. Contrary to all the other arts, its purpose is to invade a kind of despotism (the structural logic of classicism) and turn arts into a stage for exerting this invasion (" the use of breakthrough"). Mahler's music has shaken the foundation of a confident aesthetic order, in which an infinite nature is surrounded by limited tonality. This closed and stable construction (i.e. the classical structural concept) is attacked from the outside (because no music materials which have already appeared in the works are used), and it was invaded and divided.

Adorno thinks that the second movement of Mahler's Symphony No5 is the typical embodiment of this type. The general tone here is a minor dominated by stormy and gloomy mood. In this movement, the "breakthrough" part is a piece of chorus in d major (section 464 - 519), which expresses the longing for heaven. The hymn intrudes unprepared and unpredicted, which is used as a "breakthrough" in timbre and function, and doesn't seem to belong to this movement. It is also the sudden insertion of this part that broke the original sonata structure in the movement.

"Suspension" is similar to a part of a movement that is divided in its structural form. It adopts the existing materials in the movement instead of using new materials, which plays a role in blocking the mood of the movement. The dynamics of the whole movement suddenly disappears in this part.

The post fragment (256 - 346 bar) in the third movement of Mahler's Symphony No.3 is a typical example of "suspension". The character of this part is portrayed by the material "as if from a distance" (Mahler's own mark) played by post horn. The quiet and solemn "hanging" segment is in sharp contrast with other never-ending paragraphs in the movement.

"Completion" refers to the unexpected ending feeling in music, which is similar to the "Abgesang" part of "bar form" used by lovers of poets and famous singer medieval Germany. Although this part has the function of reproduction, it does not rule out the appearance of new materials. The completion of music content can be achieved by very new materials, which conflicts with the inherent closed concept of music. This technique seems to suggest that Mahler yearned 
for the early "natural and essential" times more, while he was full of disgust at the modern and mechanized times. The same technique is reflected in the first movement of Mahler's Symphony No3, the last part of the reproduction part of the last movement of the Sixth Symphony and the first movement of The Song of The Earth.

Mahler's characteristic artistic treatment (breakthrough, suspension and completion) breaks the tight logical structure and relatively closed system in the symphony created by Beethoven, as well as the compactness, structural strength and overall aesthetic feeling of the symphony form constructed by this system. Mahler's unique structural theory liberated music from the so-called classical "overall aesthetic experience". The overall framework of symphony which is similar to the traditional musical structure implies the integrity of society, while those parts which he divided into "breakthrough", "suspension" and "completion" represent the victims or victims of society. Therefore, Mahler's heart actually hides the dissimilation state formed in the contradiction and conflict between individual and society in the life state that looks the same as ordinary people.

\section{CONCLUSION}

To sum up, all kinds of representations of alienation narrative in Mahler's music are real expressions of alienated society at that time, and they have profound social causes. Mahler's own triple homelessness caused his spiritual wandering and floating doomed to life. Cruel historical reality is the root of Mahler's tragic fate. Decadent thoughts at the Fin-de-Siècle in Vienna and persecution by Anti Semitism all his life are cruel realities that Mahler himself cannot change. Mahler's special social identity caused a series of psychological problems, which finally contributed to his deep conversion of inner anxiety and suspicion, yearning and despair, irony and ridicule of social alienation into strings of notes in music. Among them, the most important religious plot from death to life profoundly reflects an alienation direction which is abandoned by society and strongly alienates the heart from society. Therefore, the dissimilation narrative in Mahler's music has deeper social significance. It is a representation of social abnormal phenomenon, a representation of the loneliness and helplessness, fear and despair of human existence, a revelation and criticism of social phenomena and current political abuses. It also demonstrates the eternal artistic value of Mahler's music from this angle because great art always reflects and criticizes social reality.

This phenomenon of "alienation" has not disappeared with the passage of time today, which is caused by various social contradictions and living pressures that human beings are facing. People are anxious and suspicious, but they are struggling to find and pursue. They pursue and seek, but often fall into disillusionment and despair. All these can be found in Mahler's "musical narrative" with surprising similarities and resonance. Mahler's unique voice of personality will surely become a kind of special "revelation" of humanistic spirit, which will accompany with the development of human civilization for a long time.

\section{REFERENCES}

[1] Yang Yandi, "Mahler's postmodern meaning", Art review, No.5, 2011.

[2] Yu Runyang: "Investigation of a social school's philosophy of music (I) - interpretation and comment on Adorno's philosophy of new music", Chinese musicology, No.1, 1995.

[3] Yu Runyang: "Investigation of a social school's philosophy of music (II) - interpretation and comment of Adorno's philosophy of new music", Chinese musicology, No.2, 1995

[4] Sun Sisi:"Adorno's Mahler view" - comments on "Mahler: a musical mental analysis", Huang Zhong (journal of Wuhan conservatory of music, China), No.1, 2011.

[5] Sun Sisi, "Spiritual search at the Fin-de-Siècle": the study of Mahler's three medium-term symphonies, Doctoral thesis of Shanghai conservatory of music, 2012.

[6] Qiu Shiyue Changche: "Compassion and loneliness: lost existenceon the 'alienation' phenomenon in the narrative of Chinese modern urban novels", Northern theory cluster, No.5, 2012.

[7] Sun Guozhong: "Mahler's centennial sacrifice", Huang Zhong, No.4, 2011. 